\title{
A Novel Technique of Intradiverticular Papillary Canulation Aided by EVL Band Ligator in a Case of Lemmel's Syndrome
}

\author{
Shanmuganathan Subramanyam ${ }^{1}{ }^{10}$ Vatsal Bachkaniwala ${ }^{1} \quad$ Chunduri V.V. Vikranth $^{1}$ P. Ganesh ${ }^{1}$ \\ ${ }^{1}$ Department of Medical Gastroenterology, Sri Ramachandra Institute \\ of Higher Education and Research, Chennai, Tamil Nadu, India \\ Address for correspondence Chunduri V.V. Vikranth, MBBS, MD \\ (General medicine), Department of Medical Gastroenterology, Sri \\ Ramachandra Institute of Higher Education and Research, Mount \\ J Digest Endosc 2022;13:50-52. \\ Poonamallee Road, Chennai 600116, Tamil Nadu, India \\ (e-mail: chvv.vikranth@gmail.com).
}

\author{
Abstract \\ Keywords \\ - intradiverticular \\ papilla \\ - Lemmel's syndrome \\ - duodenal \\ diverticulum
}

A duodenal periampullary diverticulum can cause changes in the local anatomy and pose a challenge for the cannulation of the bile duct. Cannulation may be much more difficult if the ampulla is located within the diverticula. We present the case of a 40year-old man who developed obstructive jaundice and cholangitis because of the duodenal diverticula mechanically obstructing the common bile duct (Lemmel's syndrome). The papilla was located entirely within the duodenal diverticula and was brought out after placing endoscopic variceal ligation (EVL) bands. Biliary access and stenting could be done easily, after exposing the papilla. There were no complications during the procedure or the recovery period.

\section{Introduction}

The periampullary diverticulum (PAD) is a duodenal outpouching near the major duodenal papilla. PAD is seen in $9 \%$ to $32.8 \%$ of patients undergoing endoscopic retrograde cholangiopancreatography (ERCP). ${ }^{1}$ The majority of the PAD are asymptomatic and are diagnosed incidentally during computed tomography (CT) or ERCP. In rare instances, they can cause pancreaticobiliary complications such as obstructive jaundice because of the mechanical effect of the diverticulum (Lemmel's syndrome). ${ }^{2}$ Apart from the clinical significance, they often pose technical challenges during the ERCP. The papillary opening is often seen either at the superior or the inferior border of the PAD. However, when the papilla is entirely within the PAD, the orientation changes making cannulation of the bile duct problematic.
In this case report, we look at a novel way to get around this problem by using a band ligator to uncover the papilla out of PAD.

\section{Case Report}

A 40-year-old man presented with features of obstructive jaundice, abdominal pain, and fever for the past 2 weeks. His physical examination revealed icterus and mild tenderness in the right hypochondrium. Laboratory investigations showed elevated total counts $\left(15,000\right.$ cells $\left./ \mathrm{mm}^{3}\right)$ total bilirubin of $9.8 \mathrm{mg} / \mathrm{dL}$, direct bilirubin $6.38 \mathrm{mg} / \mathrm{dL}$, SGOT $83 \mathrm{IU} / \mathrm{L}$, SGPT $103 \mathrm{IU} / \mathrm{L}$, alkaline phosphate $481 \mathrm{IU} / \mathrm{L}$, and gamma GT $566 \mathrm{U} / \mathrm{L}$.

A CT scan of the abdomen showed a periampullary diverticulum measuring $2 \mathrm{~cm} \times 1 \mathrm{~cm}$ in the second part of the duodenum compressing the intrapancreatic distal

(c) 2022. Society of Gastrointestinal Endoscopy of India. All rights reserved.

This is an open access article published by Thieme under the terms of the Creative Commons Attribution-NonDerivative-NonCommercial-License, permitting copying and reproduction so long as the original work is given appropriate credit. Contents may not be used for commercial purposes, or adapted, remixed, transformed or built upon. (https://creativecommons.org/ licenses/by-nc-nd/4.0/)

Thieme Medical and Scientific Publishers Pvt. Ltd., A-12, 2nd Floor, Sector 2, Noida-201301 UP, India 
common bile duct (CBD) causing upstream dilatation of the CBD, common hepatic duct (CHD), and intrahepatic biliary radicles (IHBR). No calculi were seen in the biliary system. The above features were suggestive of Lemmel's syndrome.

The patient was started on broad-spectrum antibiotic coverage along with intravenous fluids. He was taken up for an emergency ERCP to relieve the biliary obstruction. During the procedure, two large diverticula were visualized on the medial wall of the second part of the duodenum.

The ampullary ridge was identified at the mouth of one of the diverticulum but the papilla could not be visualized. A biopsy forceps were used to pull and confirm the position of the papillary opening within the diverticulum (-Fig. 1). Biliary cannulation was attempted but was unsuccessful. A marking was made using the same forceps at the ampullary ridge for later identification. The placement of a hemoclip at the marked site was attempted but failed due to technical difficulties. The duodenoscope was withdrawn entirely, and a forward view scope was introduced with an EVL band ligator (COOK 6 Shooter ${ }^{\circledR}$ Universal Saeed ${ }^{\circledR}$ Multi-Band Ligator).

Two bands were deployed at the previously marked site (-Fig. 2A) with the intent to evert the edge of the diverticulum within which the ampullary opening was hidden. The duodenoscope was reintroduced, and the papillary opening was clearly visible. The papilla was easily cannulated, and biliary access was obtained (-Fig. 2B). Cholangiogram showed a distal CBD narrowing with dilatation of proximal CBD, CHD, and IHBR, without any evidence of choledocholithiasis or stricture, thus confirming Lemmel's syndrome

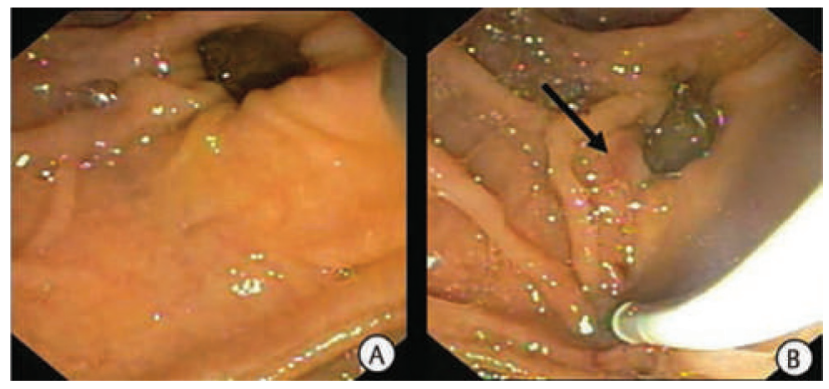

Fig. 1 (A) Periampullary diverticulum with the hidden intradiverticular papilla. (B) Papillary opening (black arrow) seen after pulling the caudal portion of diverticulum below the ampullary ridge.

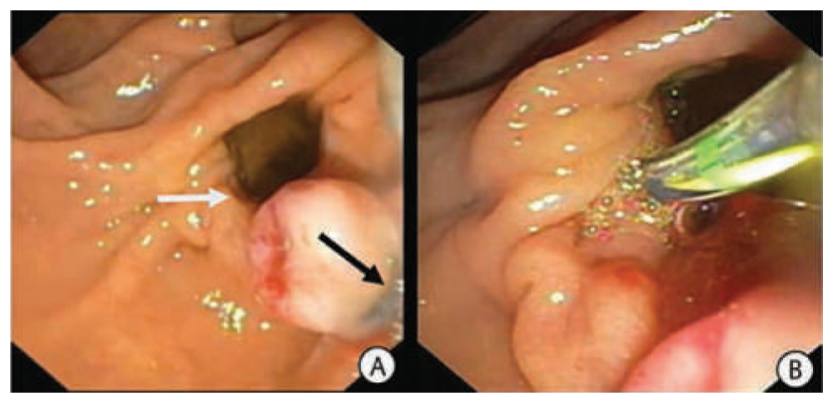

Fig. 2 (A) Side view endoscopy with a papillary opening (white arrow) facing the duodenal lumen after successfully applying two EVL bands (black arrow). (B). Successful cannulation of the papillary opening post EVL band application.
(-Fig. 3). A sphincterotomy was done and a CBD stent was placed.

There were no complications either during or after the procedure. The patient's clinical and biochemical status improved after the procedure, and he was discharged 3 days later.

\section{Discussion}

The duodenal diverticulum is a mucosal or submucosal outpouching of the duodenal wall with a partially weak muscle. They are most commonly found in the second part of the duodenum near the periampullary region. ${ }^{3}$ PAD is uncommon in young and increases in prevalence with age; the overall prevalence among the elderly is estimated to be $65 \%{ }^{4}$

PAD is usually asymptomatic and discovered incidentally, but it can cause various pathological manifestations, including CBD obstruction, pancreatitis, perforation, bleeding, and, in rare cases, carcinoma., ${ }^{5,6}$ Lemmel's syndrome was first described in 1934 as obstructive jaundice caused by a periampullary duodenal diverticulum in the absence of choledocholithiasis. PAD causes mechanical compression of the intrapancreatic CBD with resultant upstream dilatation of the extra- and intrahepatic bile ducts. ${ }^{2}$

This syndrome presents a unique challenge for the endoscopist. The ampulla can be difficult to visualize because it is buried within the diverticular wall. Identifying and cannulating the ampulla can be done in a variety of ways, including two devices in one-channel method, reversed guidewire method, double endoscope method, balloon dilation of the narrow diverticular neck, endoclip-assisted cannulation, and cap-assisted cannulation. The success rate of these methods ranges from $80 \%$ to $100 \%$ with complication rates ranging from $4 \%$ to $25 \%{ }^{7}$ However, these methods require either an additional accessory or technical expertise.

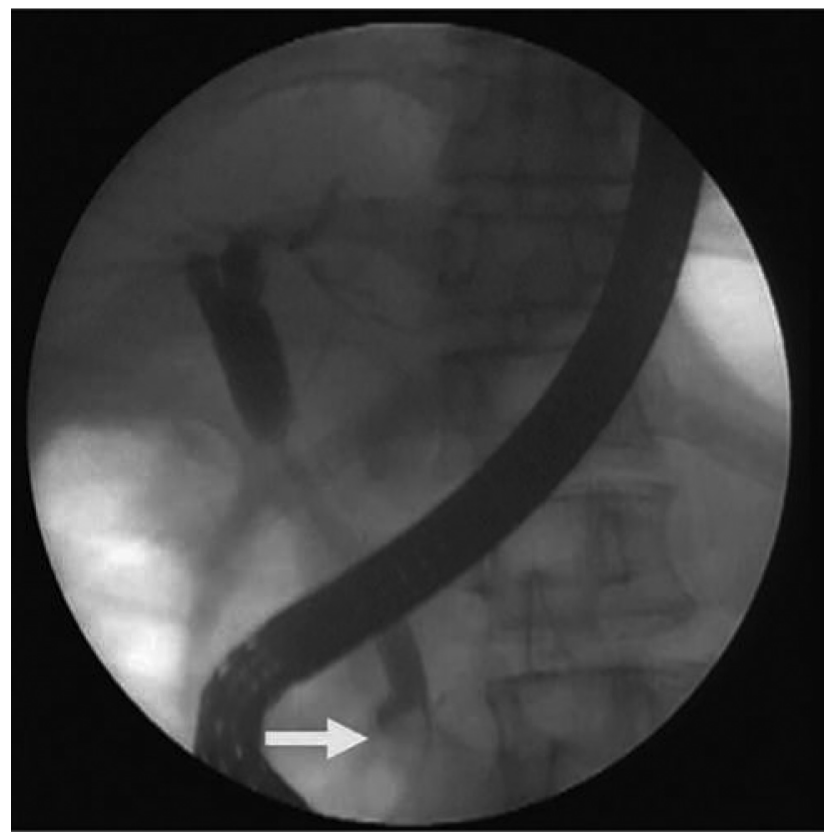

Fig. 3 Cholangiogram showing a distal CBD narrowing (white arrow) with dilatation of the proximal CBD, CHD, and IHBR. 
In our case, we used a simple and easily available EVL band ligator to retract the ampulla from the PAD. After the band placement ampullary opening is easily visualized and we achieved quick and easy cannulation in the first attempt. To the best of our knowledge, this is the first time in the literature to use the EVL band ligator in assisting ERCP. There are certain limitations with this method, exposure of ampulla after the banding can only be assessed after we reintroduce the duodenoscope. Inadvertent capturing of the full thickness of the diverticular wall, the risk of bleeding after tissue necrosis, and the need for repeated banding during follow-up procedures should also be kept in mind when attempting this technique. Further studies of this method are needed to assess the clinical outcomes and complications.

In conclusion, the technique provides an alternative and elegant method of gaining biliary access without the need to learn any additional skills.

\section{Conflict of Interest}

None declared.

\section{References}

1 Lobo DN, Balfour TW, Iftikhar SY. Periampullary diverticula: consequences of failed ERCP. Ann R Coll Surg Engl 1998;80(05): 326-331

2 Lemmel G. Die klinische Bedeutung der Duodenaldivertikel. Arch Verkrcht 1934;56:59-70

3 Sfarti VC, Bălan G Jr, Chiriac AŞ, et al. Endoscopic retrograde cholangiopancreatography (ERCP) in patients with periampullary diverticula. Rom J Morphol Embryol 2018;59(03):833-837

4 Shemesh E, Klein E, Czerniak A, Coret A, Bat L. Endoscopic sphincterotomy in patients with gallbladder in situ: the influence of periampullary duodenal diverticula. Surgery 1990;107(02): 163-166

5 Oddo F, Chevallier P, Souci J, et al. Radiologic aspects of the complications of duodenal diverticula [article in French]. J Radiol 1999;80(02):140

6 Yoneyama F, Miyata K, Ohta H, Takeuchi E, Yamada T, Kobayashi Y. Excision of a juxtapapillary duodenal diverticulum causing biliary obstruction: report of three cases. J Hepatobiliary Pancreat Surg 2004;11(01):69-72

7 Altonbary AY, Bahgat MH. Endoscopic retrograde cholangiopancreatography in periampullary diverticulum: the challenge of cannulation. World J Gastrointest Endosc 2016;8(06):282-287 